\title{
Is Previous Transanal Endoscopic Microsurgery for Early Rectal Cancer a Risk Factor of Worse Outcome following Salvage Surgery? A Case-Matched Analysis
}

\author{
Audrius Dulskas ${ }^{a, b, c}$ Aivaras Atkociunas $^{d} \quad$ Alfredas Kilius $^{a} \quad K^{2}$ estutis Petrulis ${ }^{a}$ \\ Narimantas E. Samalavicius ${ }^{a}$ c, e \\ a Department of Abdominal and General Surgery and Oncology, National Cancer Institute, Vilnius, Lithuania; \\ ${ }^{\mathrm{b}}$ Faculty of Health Care, University of Applied Sciences, Vilnius, Lithuania; \\ ${ }^{\mathrm{c}}$ Clinic of Internal, Family Medicine and Oncology, Faculty of Medicine, Vilnius University, Vilnius, Lithuania; \\ ${ }^{\mathrm{d}}$ Faculty of Medicine, Vilnius University, Vilnius, Lithuania; \\ e Department of Surgery, Klaipeda University Hospital, Klaipeda, Lithuania
}

\section{Keywords}

Rectal cancer - Total mesorectal excision - Transanal endoscopic mircrosurgery · Salvage total mesorectal excision

\section{Abstract}

Introduction: Transanal endoscopic microsurgery (TEM) is a minimally invasive procedure which allows local excision of early-stage rectal cancer and can be used as an alternative treatment to radical surgery. Patients can undergo salvage total mesorectal excision (sTME) following TEM after finding of unfavourable histological features. This study aimed to compare results and possible complications of sTME following TEM and primary TME (pTME) procedures. Methods: Between 2010 and 2017, early sTME was performed in 9 patients at the National Cancer Institute in Vilnius, Lithuania. These patients were compared with 18 patients who underwent pTME, matched according to gender, age, cancer stage, and operative procedure. Data were obtained from the patients' charts and reviewed prospectively. We recorded the demographics, tumour specifications, treatment, operation time, postoperative results complications, and oncological outcome. Fisher's exact test and student's T test was used to compare both groups. Results: A total of 130 patients underwent TEM at our institution during the study

Data from this manuscript have in part been presented at the 9th Congress of the Baltic Association of Surgeons (Klaipeda, Lithuania; May 10-12, 2018). period, of which 9 (6.92\%) had to undergo sTME. The average age of the patients was $62.7 \pm 7.07$ years; $44.4 \%$ of the patients were male and $55.6 \%$ female. The average tumour size in the sTME group was $2.8 \pm 1.05 \mathrm{~cm}$ (range $1.5-5$ ) and $2.61 \pm 1.36 \mathrm{~cm}$ (range 1-5) in the pTME group ( $p=0.696)$. When comparing postoperative complications, statistically significant results were not found in either of the groups $(p=0.55)$. Operation time of pTME was significantly shorter on average, i.e. $43 \mathrm{~min}$, compared to sTME ( $p<0.0267)$. The average number of harvested lymph nodes was $12.44 \pm 7.126$ in the sTME and $12.5 \pm 8.06$ in the pTME group ( $p=0.986)$. The circumferential resection margin (CRM) was negative in $92.6 \%$ $(25 / 27)$ of specimens, while the CRM was positive in 2 cases $(7.4 \%)$, both of which were from the sTME group. The average follow-up time was 22.8 months (8-80 months) for patients undergoing sTME and 19.33 months (2-88 months) for patients after pTME $(p=0.71)$. Conclusions: TEM is a relatively safe method for treating patients with early rectal cancer without high-risk features. It can be used in exceptional cases with high-risk features when the patient is not fit for radical surgery.

(C) 2018 S. Karger AG, Basel

\section{Introduction}

Colorectal cancer (CRC) is the third most common site of cancer as well as the fourth most common cause of death from cancer worldwide [1]. For decades, there has been an increasing preva-

\section{KARGER}

() 2018 S. Karger AG, Basel
Audrius Dulskas, MD, PhD 
lence of CRC in Lithuania [2]. This was the reason for searching for the most optimal way of treatment that could not only assure a longer life span but which would also avoid a decrease of the patients' quality of life.

Transanal endoscopic microsurgery (TEM) is a minimally invasive surgical procedure that allows a clear magnified stereoscopic view of the rectum. Controlled endoscopically, this method provides an opportunity to perform various surgical procedures in confined spaces with ease. By means of minimally invasive surgery, it is possible to perform a full local excision of early-stage rectal cancer. In the 1980s, Buess et al. [3] introduced TEM to the world. Since then, minimally invasive surgery has been slowly employed as an alternative treatment in selected patients with early-stage rectal cancer and favourable histological characteristics or, combined with total mesorectal excision (TME), which had been the gold standard for a long time, in patients not fit for rectal resection [4]. However, TME is associated with a higher risk of postoperative mortality and morbidity [5-7]. TME is also accompanied by pelvic organ dysfunction: bowel movement impairment (up to 80\%), sexual dysfunction (up to 30\%), and impairment of urinary function (up to 10\%), and it is also known as low anterior resection syndrome $[5,8]$. These postoperative complications have a major impact on the patients' quality of life, whereas TEM is associated with low morbidity and mortality [7-10]. However, local recurrence after TEM is a major problem in up to $24 \%$ of patients treated for rectal cancer by this method $[2,11-15]$. If a more advanced cancer stage (more than pT1 sm1) is found in TEM specimen or if the tumour is poorly differentiated, a salvage TME (sTME) procedure is indicated in these patients [16].

In the present case-matched study, we aimed to determine whether there is a significant difference between outcomes in patients with early-stage rectal cancer who underwent sTME after TEM and in those who underwent primary TME (pTME).

\section{Patients and Methods}

The study was approved by the Institutional Review Board.

We conducted a prospective study from retrospectively gathered data covering information on patients who had been treated for early rectal cancer at our department from 2010 to 2017. During the study period, 690 patients were treated for rectal tumours, 130 of them underwent TEM, and 9 patients underwent sTME later. These patients were compared with those that had undergone pTME for early rectal cancer during the same period of time. Patients were matched on the basis of gender, cancer stage, operative procedure, and age characteristics. We analysed the demographics of the patients, tumour specifications, duration of procedures, postoperative results, complications, and oncological outcomes. Postoperative complications were characterised according to the Clavien-Dindo classification [17].

All patients of our study were evaluated preoperatively according to a standard protocol; this included physical and endoscopic examination as well as biopsy of the tumour. The patients also underwent endorectal ultrasonography (EUS) or magnetic resonance imaging (MRI) for evaluation.

Data was entered in Microsoft Office Excel 2013, and calculated and analysed in IBM SPSS Statistics 23.0 (IBM Corp., Armonk, NY, USA). Proportions were compared by Fisher's exact test. Student's T test was used to compare normally distributed variables. $\mathrm{P}$ values less than 0.05 were considered significant.

\section{Results}

The patient and tumour characteristics for the two groups are shown in table 1 . The two patient groups were compared using the matched case-control analysis method; due to the difference of demographic data, means between groups were not statistically significant. The mean age was $62.56 \pm 7.98$ years in the sTME group and $62.79 \pm 6.82$ years in the pTME group. Both groups had the same proportion of male and female patients, i.e. 4 (44.4\%) male and $5(55.5 \%)$ female patients in the sTME group as well as 8 (44.4\%) male and 10 (55.5\%) female patients in the pTME group. Comorbidities were encountered by $66.7 \%$ of patients in the sTME group and by $66.6 \%$ in the pTME group. A more detailed distribution of comorbidities between the groups is shown in table 1 . The average tumour size was $2.82 \pm 1.05 \mathrm{~cm}$ (range $1.5-5 \mathrm{~cm}$ ) in the sTME group and $2.61 \pm 1.36 \mathrm{~cm}$ (range $1-5 \mathrm{~cm}$ ) in the pTME group. The majority of tumours in the sTME group, i.e. 4 (44.4\%), was located in the middle part of the rectum, with $2(22.2 \%)$ being in the proximal rectum and $3(33.3 \%)$ in the distal rectum. In the pTME group, most tumours, i.e. 8 (44.4\%), were also located in the middle rectum, but a higher percentage was found in the proximal rectum, i.e. $6(33.3 \%)$, while a lesser percentage compared to the sTME group was found in the distal rectum, i.e. 4 (22.2\%). However, the difference between the groups was not statistically significant $(\mathrm{p}=0.765)$. During sTME, tearing of the bowel wall occurred in 2 patients (22.22\%). The pathological analysis of surgical specimen showed a complete mesorectum (M.E.R.C.U.R.Y. I ${ }^{\circ}$ [18]) in $92.6 \%(25 / 27)$ of the removed tumours. None (0/27) of the mesorectum was nearly complete (M.E.R.C.U.R.Y. II $\left.^{\circ}\right)$, and $7.4 \%(2 / 27$ - 2 tumours from the sTME group) of the removed tumours had an incomplete mesorectum (M.E.R.C.U.R.Y. III'). The circumferential resection margin (CRM) was negative in 92.6\% (25/27) and positive in $7.4 \%(2 / 27)$ of specimens.

When comparing the lengths of operating time between the groups, it was noticed that the procedures took statistically significantly longer in the sTME group than in the pTME group (average length of operating time: sTME group 165 min vs. pTME group $122 \mathrm{~min}(\mathrm{p}<0.03))$. There also was a tendency of a longer hospital stay, with an average of $13.2 \pm 9.68$ days in the sTME group compared to $9.11 \pm 2.44$ days in the pTME group $(p=0.097)$. Lymph node harvest was $12.44 \pm 7.126$ and $12.5 \pm 8.06$ in the sTME and the pTME group $(\mathrm{p}=0.986)$, respectively. Early postoperative complications occurred in 2 patients $(22.2 \%)$ in the sTME group and could be characterised as grade IIIa according to the ClavienDindo classification; in the pTME group, 3 patients (16.7\%) had complications which could be characterised as grade I, II and III according to the Clavien-Dindo classification of surgical complications. Detailed data are shown in table 2. The average follow-up time was 22.8 months (8-80 months) for patients who underwent sTME and 19.33 months (2-88 months) for patients after pTME (p $=0.71$ ). The overall survival (OS) was the same in both groups and reached $100 \%$; the very same was observed regarding the 5-year disease-free survival (DFS), which also reached $100 \%$ in both groups. 
Table 1. Patient and tumour characteristics of the salvage total mesorectal excision (sTME) and primal total mesorectal excision (pTME) groups
Table 2. Intraoperative and postoperative data with oncological results

\begin{tabular}{|c|c|c|c|}
\hline Groups & sTME & pTME & $\mathrm{p}$ \\
\hline Number of patients & 9 & 18 & \\
\hline Age (mean $\pm S D$, range), years & $62.56 \pm 7.98(48-72)$ & $62.78 \pm 6.82(48-75)$ & 0.94 \\
\hline Gender & $\begin{array}{l}\text { male: } 4(44.4 \%) \\
\text { female: } 5(55.6 \%)\end{array}$ & $\begin{array}{l}\text { male: } 8(44.4 \%) \\
\text { female: } 10(56.6 \%)\end{array}$ & 1 \\
\hline \multicolumn{4}{|l|}{ Comorbidity } \\
\hline 1 & $5(55.6 \%)$ & $9(50 \%)$ & \\
\hline 2 & 0 & 0 & \\
\hline 3 & 0 & $1(5.6 \%)$ & \\
\hline 4 & $1(11.1 \%)$ & 0 & \\
\hline \multicolumn{4}{|l|}{ Tumour distance from anal verge, $\mathrm{cm}$} \\
\hline$<6$ & $3(33.3 \%)$ & $4(22.2 \%)$ & \\
\hline $6-10$ & $4(44.4 \%)$ & $8(44.4 \%)$ & 0.765 \\
\hline$>10$ & $2(22.2 \%)$ & $6(33.3 \%)$ & \\
\hline Tumour size, $\mathrm{cm}$ (mean $\pm \mathrm{SD}$, range) & $2.82 \pm 1.05(1.5-5)$ & $2.61 \pm 1.36(1-5)$ & 0.696 \\
\hline
\end{tabular}

\begin{tabular}{|c|c|c|c|}
\hline & sTME group & pTME group & $\mathrm{p}$ \\
\hline Operative time, mean $\pm \mathrm{SD}$ ( range) & $165 \pm 39.92(90-220)$ & $122 \pm 46.9(45-210)$ & 0.0267 \\
\hline $\begin{array}{l}\text { Hospital stay, mean } \pm \text { SD ( range) } \\
\mathrm{T}\end{array}$ & $13.2 \pm 9.68(2-33)$ & $9.11 \pm 2.44(6-14)$ & 0.097 \\
\hline 0 & $8(88.9 \%)$ & 0 & \\
\hline 1 & 0 & $11(61.1 \%)$ & \\
\hline 2 & $1(11.1 \%)$ & $7(38.9 \%)$ & \\
\hline Harvested lymph nodes, mean (range) & $12.44(2-22)$ & $12.5(0-38)$ & 0.986 \\
\hline Complications, $\mathrm{n}(\%)$ & $2(22.2 \%)$ & $3(16.7 \%)$ & 0.55 \\
\hline Wound sepsis & 1 & & \\
\hline Urinary retention & & 1 & \\
\hline \multicolumn{4}{|l|}{ Anastomosis leakage } \\
\hline Fever & 1 & 1 & \\
\hline Urinary tract infection & & 1 & \\
\hline Fistula & 2 & & \\
\hline Postoperative bleeding & 1 & & \\
\hline
\end{tabular}

\section{Discussion}

TEM is associated with low morbidity and mortality and should be considered a safe and effective technique for treating early-stage pT1 sm1 rectal cancer [7-10, 19]. Recently, two studies with similar design have been published [20,21]. Bulot et al. [20] compared 25 patients undergoing early salvage surgery with TME after TEM with 25 patients who underwent primary TME. The patients were matched according to gender, age ( \pm 2 years), cancer stage, and operative procedure. The authors concluded that TEM can be chosen as a primary treatment in selected patients, as the outcome was not compromised by the following abdominal rectal resection plus TME. However, Mistrangelo et al. [21] pointed out that the latter study included both early (stage I) and locally advanced (stage II) rectal cancers that were treated without neoadjuvant therapy and only by TEM, and that the interpretation of the results is biased by the fact that the groups were matched according to several variables. Thus, they underestimated the risk of abdominoperineal resection (APR) after failure of transanal local excision for rectal cancer, as it is reported in the literature. Mistrangelo et al. [21] compared 17 patients that underwent TEM followed by laparoscopic TME (LTME) with 34 patients undergoing primary LTME, and showed that LTME after TEM is associated with a significantly higher risk of APR than primary TME [22]. The authors stated that a fibrotic scar, the development of which is caused by full-thickness TEM, makes dissection of the correct planes down to the pelvic floor harder.

In our study, we found the operating time to be significantly longer (i.e. by $43 \mathrm{~min}$ ) in the sTME group compared to pTME. The longer duration of surgical procedures can be explained by the challenging TME after TEM due to the development of a fibrotic scar or the perforation of a lesion during dissection due to a previous full-thickness TEM operation. However, as we found in our study, such a fibrotic scar had no major impact on postoperative complications. Nevertheless, we had 2 cases (22.22\%) of bowel perforation in the sTME group. Reduction of these occurrences could be achieved by an awareness of this possible complication and by an increased focus during the operation of patients who have previously undergone TEM. 
In their meta-analysis published in 2004, Bipat et al. [23] reached the conclusion that EUS is superior to MRI in terms of accuracy in defining tumour stages in rectal cancer patients. However, the studies included in this meta-analysis were published before 2002 when the diagnostic experience of clinical practitioners was insufficient and resulted in poor performance of MRI. Li et al. [24] published a new meta-analysis on the evaluation of rectal tumour staging in 2016. 89 studies with an overall of 9,141 patients were included. The authors concluded that MRI should be recommended for rectal cancer patients as the radiologic examination method of choice, while EUS provides a complementary method after MRI examination for patients with early-stage cancer.

In our own study, the average follow-up time was 22.8 months (8-80 months) for patients undergoing sTME and 19.33 months $(2-88$ months) in those with pTME ( $\mathrm{p}=0.71)$. The OS and DFS of patients reached $100 \%$ in both groups. In previously published studies, various percentage values are given for OS: Hompes et al. [25] observed a 5 -year OS of $83 \%$ and a 5 -year DFS of $74 \%$, whereas Hahnloser et al. [26] found $79 \%$ and $94 \%$, respectively, and Nakagoe et al. [27] documented $100 \%$ for both, just like in our study.

In medium-risk pT1/pT2 rectal cancer, a preservation of rectum regimen with adjuvant chemoradiotherapy after TEM could be an alternative to sTME. In 2016, Borstlap et al. [28] published a metaanalysis in which they analysed oncological outcomes after local excision of pT1-2 rectal cancer requiring adjuvant (chemo-)radiotherapy or completion surgery. They showed that outcome data of local excision with adjuvant (chemo-)radiotherapy is quite variable. Sun et al. [29] reached a 5-year OS of $63 \%$ for patients with T1 rectal cancer treated with local excision only, and Gopaul et al. [30] demonstrated better results with a 5 -year OS of $71 \%$ and a 5 -year DFS of $83 \%$, while the best results were shown by Min et al. [31], with a 5 -year DFS of $100 \%$ for patients with T1 rectal cancer. sTME is still considered the standard procedure after endoscopic resection of high-risk pT1 and pT2 rectal cancer. However, adjuvant radiotherapy might be investigated as a less invasive method of treat- ment compared to sTME in selected patients with intensive followup [28].

Birdbeck et al. [32] have shown that the CRM is a clear predictor of both OS and the risk of local recurrence. If a tumour has lateral clearance of less than $1 \mathrm{~mm}$, it has a much greater probability of recurrence [33]. A negative effect on local recurrence and OS is caused by intraoperative perforation [34]. Achieving a negative CRM and avoiding perforation is a challenge, especially for low rectal lesions, which usually are full thickness and incorporate some of the mesorectum around the tumour. In our study, 2 patients had a tearing of the bowel wall which occurred during sTME. This did not affect the oncological outcomes of the patients, although it did have an effect on the postoperative course - both patients had fistulas, 1 patient also had wound sepsis, while postoperative bleeding had occurred in the other one. In order to create an intact and non-perforated specimen with adequate distant resection margins and CRMs while following correct TME dissection planes, hybrid transanal and laparoscopic TME for low rectal cancer can be used $[35,36]$.

\section{Conclusions}

TEM is a relatively safe method for treating patients with early rectal cancer, when the patient is not fit for radical surgical procedures due to comorbidities. Even though sTME after TEM is a challenging procedure and a previous TEM represents a risk factor for an increased rate of intraoperative bowel perforation, it is not associated with increased morbidity or mortality. These conclusions may be biased due to the small numbers and the retrospective design of the study and should therefore be considered with caution.

\section{Disclosure Statement}

The authors have no conflicts of interest to declare.

\section{References}

1 Global Burden of Disease Cancer Collaboration; Fitzmaurice C, Dicker D, Pain A, et al: The global burden of cancer 2013. JAMA Oncol 2015; 1:505-527.

$>2$ Dulskas A, Kilius A, Petrulis K, Samalavicius NE: Transanal endoscopic microsurgery for patients with rectal tumors: a single institution's experience. Ann Coloproctol 2017;33:23-27.

3 Buess G, Mentges B, Manncke K, Starlinger M, Becker HD: Technique and results of transanal endoscopic microsurgery in early rectal cancer. Am J Surg 1992; 163:63-70.

4 Heald RJ, Moran BJ, Ryall RD, Sexton R, Mac Farlane JK: Rectal cancer: the Basingstoke experience of total mesorectal excision 1978-1997. Arch Surg 1998;133: 894-899.

5 Arezzo A, Passera R, Scozzari G, Verra M, Morino M: Laparoscopy for rectal cancer reduces short-term mortality and morbidity: results of a systematic review and meta-analysis. Surg Endosc 2013;27:1485-1502.
6 Blair S, Ellenhorn JD: Transanal excision for low rectal cancers is curative in early-stage disease with favorable histology. Am Surg 2000;66:817-820.

7 Heintz A, Mörschel M, Junginger T: Comparison of results after transanal endoscopic microsurgery and radical resection for $\mathrm{T} 1$ carcinoma of the rectum. Surg Endosc 1998;12:1145-1148.

8 Samalavicius NE, Dulskas A, Lasinskas M, Smailyte G: Validity and reliability of a Lithuanian version of low anterior resection syndrome score. Tech Coloproctol 2016;20:215-220.

9 de Graaf EJ: Transanal endoscopic microsurgery. Scand J Gastroenterol Suppl 2003;239:34-39.

10 de Graaf EJ, Doornebosch PG, Tollenaar RA, Meershoek-Klein Kranenbarg E, de Boer AC, Bekkering FC, van de Velde CJ: Transanal endoscopic microsurgery versus total mesorectal excision of T1 rectal adenocarcinomas with curative intention. Eur J Surg Oncol 2009;35:1280-1285.
1 Moore JS, Cataldo PA, Osler T, Hyman NH: Transanal endoscopic microsurgery is more effective than traditional transanal excision for resection of rectal masses. Dis Colon Rectum 2008;51:1026-1031.

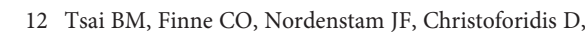
Madoff RD, Mellgren A: Transanal endoscopic microsurgery resection of rectal tumors: outcomes and recommendations. Dis Colon Rectum 2010;53:16-23.

13 de Graaf EJ, Burger JW, van Ijsseldijk AL, Tetteroo GW, Dawson I, Hop WC: Transanal endoscopic microsurgery is superior to transanal excision of rectal adenomas. Colorectal Dis 2011;13:762-767.

14 Guerrieri M, Baldarelli M, Morino M, Trompetto M, Da Rold A, Selmi I, Allaix ME, Lezoche G, Lezoche E: Transanal endoscopic microsurgery in rectal adenomas: experience of six Italian centres. Dig Liver Dis 2006;38:202-207. 
15 Middleton PF, Sutherland LM, Maddern GJ: Transanal endoscopic microsurgery: a systematic review. Dis Colon Rectum 2005;48:270-284.

16 Glynne-Jones R, Wyrwicz L, Tiret E, Brown G, Rödel C, Cervantes A, Arnold D; on behalf of the ESMO Guidelines Committee: Rectal cancer: ESMO Clinical Practice Guidelines for diagnosis, treatment and follow-up. Ann Oncol 2017;28(suppl 4):22-40.

17 Dindo D, Demartines N, Clavien PA: Classification of surgical complications: a new proposal with evaluation in a cohort of 6336 patients and results of a survey. Ann Surg 2004;240:205-213.

18 M.E.R.C.U.R.Y. Study Coordinator Daniels I, Pelican Centre, North Hampshire Hospital, Basingstoke, Hampshire, UK. 2002. (Magnetic Resonance Imaging and Rectal Cancer European Equivalence Study.) www. pelicancancer.org/researchprojects.

19 Koebrugge B, Bosscha K, Ernst MF: TEM for local excision of rectal lesions: is there a learning curve? Dig Surg 2009;26:372-377.

20 Bulut O, Levic K, Hesselfeldt P, Bulow S: The outcome of rectal cancer after early salvage TME following TEM compared with primary TME: a case-matched study. Tech Coloproctol 2014;18:83-84

21 Mistrangelo M, Allaix ME, Arezzo A, Morino M: Comments on Levic et al.: The outcome of rectal cancer after early salvage TME following TEM compared with primary TME: a case-matched study. Tech Coloproctol 2014;18:81.

22 Morino M, Allaix ME, Arolfo S, Arezzo A: Previous transanal endoscopic microsurgery for rectal cancer represents a risk factor for an increased abdominoperineal resection rate. Surg Endosc 2013;27:3315-3321.
23 Bipat S, Glas AS, Slors FJ, Zwinderman AH, Bossuyt PM, Stoker J: Rectal cancer: local staging and assessment of lymph node involvement with endoluminal US, CT, and MR imaging - a meta-analysis. Radiology 2004;232:773-783.

24 Li XT, Zhang XY, Sun YS, Tang L, Cao K: Evaluating rectal tumor staging with magnetic resonance imaging, computed tomography, and endoluminal ultrasound: a meta-analysis. Medicine (Baltimore) 2016;95:e5333.

25 Hompes R, McDonald R, Buskens C, Lindsey I, Armitage N, Hill J, Scott A, Mortensen NJ, Cunningham C; Association of Coloproctology of Great Britain and Ireland Transanal Endoscopic Microsurgery Collaboration: Completion surgery following transanal endoscopic microsurgery: assessment of quality and short- and longterm outcome. Colorectal Dis 2013;15:576-581.

26 Hahnloser D, Wolff BG, Larson DW, Ping J, Nivatvongs S: Immediate radical resection after local excision of rectal cancer: an oncologic compromise? Dis Colon Rectum 2005;48:429-437.

27 Nakagoe T, Ishikawa H, Sawai T, Tsuji T: Long-term outcomes of radical surgery after gasless video endoscopic transanal excision of T1/T2 rectal cancers. Eur J Surg Oncol 2004;30:638-642.

28 Borstlap WA, Coeymans TJ, Tanis PJ, Marijnen CA, Cunningham C, Bemelman WA, Tuynman JB: Metaanalysis of oncological outcomes after local excision of pT1-2 rectal cancer requiring adjuvant (chemo)radiotherapy or completion surgery. Br J Surg 2016;103: 1105-1116.

29 Sun G, Tang Y, Li X, Meng J, Liang G: Analysis of 116 cases of rectal cancer treated by transanal local excision. World J Surg Oncol 2014;12:202.

30 Gopaul D, Belliveau P, Vuong T, Trudel J, Vasilevsky CA, Corns R, Gordon PH: Outcome of local excision of rectal carcinoma. Dis Colon Rectum 2004;47:17801788 .
1 Min BS, Kim NK, Ko YT, Lee KY, Baek SH, Cho CH Sohn SK: Long-term oncologic results of patients with distal rectal cancer treated by local excision with or without adjuvant treatment. Int J Colorectal Dis 2007; 22:1325-1330.

32 Birbeck KF, Macklin CP, Tiffin NJ, Parsons W, Dixon MF, Mapstone NP, Abbott CR, Scott N, Finan PJ, Johnston D, Quirke P: Rates of circumferential resection margin involvement vary between surgeons and predict outcomes in rectal cancer surgery. Ann Surg 2002;235:449-457.

33 Nagtegaal ID, Marijnen CA, Kranenbarg EK, van de Velde CJ, van Krieken JH; Pathology Review Committee; Cooperative Clinical Investigators: Circumferential margin involvement is still an important predictor of local recurrence in rectal carcinoma: not one millimetre but two millimetres is the limit. Am J Surg Pathol 2002;26:350-357.

34 Bulow S, Christensen IJ, Iversen LH, Harling H; Danish Colorectal Cancer Group: Intra-operative perforation is an important predictor of local recurrence and impaired survival after abdominoperineal resection for rectal cancer. Colorectal Dis 2011;13:1256-1264.

35 Samalavičius NE, Dulskas A, Petrulis K, Kilius A, Tikuišis R, Lunevičius R: Hybrid transanal and total mesorectal excision after transanal endoscopic microsurgery for unfavourable early rectal cancer: a report of two cases. Acta Med Litu 2017;24:188-192.

36 Samalavicius NE, Dulskas A, Aliukonis V, Rackauskas R, Kilius A: Hybrid transanal and laparoscopic handassisted total mesorectal excision for low rectal cancer. ANZ J Surg 2017;87:953-954. 